\title{
The Safer Anaesthesia from Education (SAFE)® paediatric anaesthesia course: educational impact in five countries in East and Central Africa
}

DOI:

10.1111/anae. 14778

\section{Document Version}

Accepted author manuscript

Link to publication record in Manchester Research Explorer

Citation for published version (APA):

Boyd, N., Sharkey, E., Nabukenya, M., Tumukunde, J., Sipuka, N., Zyambo, M., Walker, I., Hart, J., \& Byrne-Davis, L. (2019). The Safer Anaesthesia from Education (SAFE) ${ }^{2}$ paediatric anaesthesia course: educational impact in five countries in East and Central Africa. Anaesthesia. https://doi.org/10.1111/anae.14778

\section{Published in:}

Anaesthesia

\section{Citing this paper}

Please note that where the full-text provided on Manchester Research Explorer is the Author Accepted Manuscript or Proof version this may differ from the final Published version. If citing, it is advised that you check and use the publisher's definitive version.

\section{General rights}

Copyright and moral rights for the publications made accessible in the Research Explorer are retained by the authors and/or other copyright owners and it is a condition of accessing publications that users recognise and abide by the legal requirements associated with these rights.

\section{Takedown policy}

If you believe that this document breaches copyright please refer to the University of Manchester's Takedown Procedures [http://man.ac.uk/04Y6Bo] or contact uml.scholarlycommunications@manchester.ac.uk providing relevant details, so we can investigate your claim.

\section{OPEN ACCESS}




\section{Corresponding author}

Dr Nicholas Boyd, Basement Flat, 23 Victoria Square, Bristol, BS8 4ES, UK

\section{ORIGINAL ARTICLE}

The SAFE paediatric anaesthesia course: the educational impact in five countries in East and Central Africa*

N. Boyd, ${ }^{1}$ E. Sharkey, ${ }^{2}$ M. Nabukenya, ${ }^{3}$ J. Tumukunde, ${ }^{3}$ N. Sipuka, ${ }^{4}$ M. Zyambo, ${ }^{4}$ I. Walker, ${ }^{5,6}$ J. Hart ${ }^{7}$ and L. Byrne-Davis ${ }^{7}$

1 Consultant, Department of Anaesthesia, Bristol Royal Hospital for Children, Bristol, UK

2 Registrar, Department of Anaesthesia, University College Hospital, London, UK

3 Lecturer, Department of Anaesthesia, Makerere University College of Health Sciences, Kampala, Uganda

4 Specialist, Department of Anaesthesia and Critical Care, University Teaching Hospital, Lusaka, Zambia

5 Consultant, Department of Anaesthesia, Great Ormond Street Hospital for Children NHS Foundation Trust, London; UK

6 Honorary Senior Lecturer, Department of Anaesthesia, UCL Great Ormond Street Institute of Child Health, London, UK

7 Health Psychologist, Department of Education, University of Manchester, Manchester, UK

Correspondence to: Dr N Boyd

Email: drnickboyd@gmail.com

Keywords: Africa; anaesthesia, paediatric; course; education; global health; LMIC; SAFE; training

* presented in part at the Great Ormond Street Conference, London, UK, October 2017.

Twitter: @drnickboyd; @Nabukenya8; @jonijojo; @luciebd

Short title: SAFE paediatric anaesthesia course 


\section{Summary}

There is an urgent need to improve access to safe surgical and anaesthetic care for children living in many low- and middle-income countries. Providing quality training for healthcare workers is a key component of achieving this. The three-day Safer Anaesthesia From Education (SAFE) paediatric anaesthesia course was developed to address the specific skills and knowledge required in this field. We undertook a project to expand this course across five East and Central African countries (Ethiopia, Kenya, Malawi, Uganda and Zambia) and train local faculty. This study reports the outcomes from course evaluation data, exploring the impact on knowledge, skills and behaviour change of participants. Eleven courses were conducted in a 15month period, with 381 participants attending. Fifty-nine new faculty were trained. Knowledge scores (0 - 50 scale) increased significantly from mean (SD) 37.5 (4.7) pre-course to $43.2(3.5)$ post-course $(p<0.0001)$. Skills scores ( 0 - 10 scale) increased significantly from 5.7 (2.0) pre-course to 8.0 (1.5) post-course $(p<$ 0.0001). One hundred and twenty-six participants in Malawi, Uganda and Zambia were visited in their workplace three to six months later. Knowledge and skills were maintained at follow-up, with scores of 41.5 (5.0) and 8.3 (1.4) respectively ( $p<0.0001$ compared with pre-course scores). Content analysis from interviews with these participants highlighted positive behaviour changes in the areas of preparation, perioperative care, resuscitation, management of the sick child, communication and teaching. This study indicates that the Safer Anaesthesia From Education paediatric anaesthesia course is an effective way to deliver training, and could be used to help strengthen emergency and essential surgical care for children as a component of universal health coverage. 


\section{Introduction}

Surgery and anaesthesia have historically been neglected in low- and middle-income countries (LMICs), even though the burden of surgical disease exceeds that of malaria, tuberculosis and HIV combined [1, 2]. In 2015, the World Health Assembly responded by passing a resolution to strengthen emergency and essential surgical care as a component of universal health coverage, including providing training for healthcare workers at the first-referral hospital level [3]. The greatest unmet need for surgery is in sub-Saharan Africa, where an estimated one billion people (14\% of the world's population) live [1].

Children comprise approximately half the population in sub-Saharan Africa, and it has been estimated that $85 \%$ are likely to require surgery before their fifteenth birthday [4]. Infants and children differ from adults in their anatomy, physiology, metabolism and clearance of drugs, and their emotional development. They have limited cardiovascular reserves and can deteriorate quickly when unwell. Their small size may present a technical challenge to the anaesthetist, and the surgical conditions of childhood are different to those seen in adult life. There are very few physician anaesthetists in sub-Saharan Africa, and even fewer with training in specialist paediatric anaesthesia $[5,6]$. The delivery of anaesthesia for children is, by necessity, the responsibility of a non-specialist non-physician anaesthetist, who typically receives 12 - 18 months training with little continuing education or opportunity for professional development. Many do not even own their own textbook (5). There is therefore an urgent need to address the training needs for anaesthetists caring for children in sub-Saharan Africa and other low-resource settings.

Training specialist paediatric physician anaesthetists, a recognised sub-speciality in many high-income countries, will require significant investment and will take decades to achieve. Short courses are one method of providing training for existing healthcare providers and have been used in low resource settings, for instance the Primary Trauma Care and Essential Pain Management courses, both of which have shown encouraging outcomes $[7,8]$. To address this training need, a three-day course in paediatric anaesthesia was developed in partnership between the Association of Anaesthetists (AAGBI), the World Federation of Societies of Anaesthesiologists and the Association of Anesthesiologists of Uganda, forming part of the Safer Anaesthesia From Education (SAFE) ${ }^{\circledR}$ project (see: https://www.wfsahq.org/wfsa-safer-anaesthesia-fromeducation-safe). The SAFE paediatric anaesthesia course is accompanied by a Train-the-Trainer course in order to assist in the scale, pace and sustainability of course delivery. The course employs a standardised monitoring and evaluation programme, which evaluates acceptability, learning and behaviour change [9]. The course was first piloted in Uganda in 2014, before this larger expanded project across East and Central Africa.

This study aimed to explore whether: knowledge and skills of local providers could be improved in paediatric anaesthesia using this short course model; learning would be maintained over time; and what the impact of the course would be in the clinical work of these anaesthesia providers. Here we report an analysis of the 
evaluation outcomes from a programme to expand the SAFE paediatric anaesthesia and Train-the-Trainer courses in five countries in East and Central Africa (Ethiopia, Kenya, Malawi, Uganda and Zambia).

\section{Methods}

The three-day SAFE paediatric anaesthesia course was developed by UK and USA specialist paediatric anaesthetists with experience of working in LMICs. The course content was created following a review of activity from hospitals in south-western Uganda, to ensure that the course was relevant to the type of surgery undertaken, anaesthetic techniques and equipment and drug availability [10]. The course materials were peer reviewed by anaesthetists and surgeons in Uganda, Malawi and Kenya. The course was piloted in Masaka, Uganda in July 2014 and January 2015, and refined following feedback from course participants and visiting and local faculty. The final course consisted of six lectures and ten themed modules delivered as lowfidelity simulation, case-based discussions, and skill stations (Appendix 1).

Monitoring and evaluation was conducted using the first three levels of the four-level evaluation method described by Kirkpatrick: level 1 - Reaction; level 2 - Learning; level 3 - Behaviour change [11].

Level 1: Reaction was evaluated using anonymous, structured feedback from participants at the end of the course, with each session and general feedback rated on a 10-point linear scale.

Level 2: Learning was assessed using pre- and post-course knowledge and skills testing of each delegate. Knowledge was evaluated using 50 true / false multiple choice questions (MCQ). These were piloted and refined alongside the course materials to ensure appropriate understanding and a focus on key areas of knowledge. Skills were assessed using an objective structured clinical examination (OSCE) model. Each delegate was randomly allocated to one of four clinical skills (tracheal intubation, basic life support, neonatal life support and trauma), and asked to carry out that skill while being observed by a member of the faculty. One point was given for correct completion of each essential step using structured marking criteria, and an overall mark given out of 10. Delegates completed the same OSCE station before and after the course. In addition, delegates who were followed up three to six months later repeated these tests.

Level 3: Behaviour change was evaluated by four SAFE paediatric fellows who visited course participants in their place of work three to six months after training. The fellows explored the behaviour change of the trainees during a structured face-to-face interview (Appendix 2) and a SAFE logbook, in which delegates recorded clinical cases they had managed differently as a result of attending the course. The fellows also reviewed the operating theatre logbooks, in order to estimate paediatric caseload.

Five partner countries were identified in the East and Central African region that had pre-existing links with UK paediatric anaesthetists: Ethiopia; Kenya; Malawi; Uganda; and Zambia. Twenty-four physician anaesthetists from these countries were invited to attend an inaugural SAFE paediatric anaesthesia course in Masaka, Uganda in January 2016, delivered by experienced faculty from the UK, USA and Uganda (Fig. 1). 
Immediately following this, participants attended a one-day SAFE Train-the-Trainer course, and then taught a SAFE paediatric anaesthesia course for Ugandan non-physician anaesthetists, mentored by the visiting faculty.

The regional faculty were funded to organise and teach a second round of SAFE paediatric anaesthesia and Train-the-Trainer courses in their home countries, prioritising anaesthesia providers (including trainees) in hospitals with a substantial paediatric workload. All courses included experienced SAFE faculty from the UK as well as neighbouring African countries, to encourage ongoing collaboration in the region. All courses were fully funded as part of this project including travel, board and lodging for all course attendees and funding for equipment required. Course participants were not paid a per-diem to attend training.

We intended to run two courses in each country with at least 25 anaesthetists attending per course, giving at least 250 expected participants in this evaluation. All anaesthetists who attended a SAFE course as part of the second round five country expansion project were eligible for inclusion in the evaluation. MCQ and OSCE scores for the physician anaesthetists who attended the inaugural course in Uganda were excluded from analysis, because of their pre-existing interest and training in paediatric anaesthesia.

Secondary analysis of routine course evaluation data was performed to explore the impact of the SAFE course, and identify any generalisable findings about interventions to improve anaesthetic practice. All data were anonymised and entered into Excel for Mac v16.22 (Microsoft ${ }^{\circ}$, Redmond, Washington, USA). Quantitative data analysis was performed using descriptive statistics and paired t-tests. A directed content analysis was completed for qualitative elements of course feedback and from interview data. Data were coded into themes by one of the authors (ES), and reviewed by a second author (NB) to identify the most common areas of behaviour change highlighted by course participants [12].

All data were collected in accordance with local and UK ethical principles and anonymised. The Chair of the Ethics committee at the University of Manchester deemed that ethical approval was not required for this secondary analysis of anonymised course data.

\section{Results}

A total of 381 participants attended eleven SAFE paediatric anaesthesia courses over a 15-month period from January 2016 - March 2017. Following the inaugural course in Uganda, further courses were held in Ethiopia (1), Kenya (2), Malawi (2), Uganda (3) and Zambia (2). Three hundred and thirty-five course participants (88\%) were non-physician anaesthetists (Table 1). Five Train-the-Trainer courses were conducted, training 59 new faculty. Of these, 46 (78\%) went on to teach on a SAFE paediatric course as part of this project. 
Follow-up at three to six months was completed by SAFE fellows for courses in Malawi (ES), Uganda (JT, MN) and Zambia (NS, MZ; Table 2). Follow-up was not possible in Ethiopia because of a state of emergency, and in Kenya because of extended healthcare worker strikes. After exclusion of the physician participants from the inaugural course, 192 participants were eligible for follow-up. A review of theatre logbooks from the preceding three months indicated that paediatric surgery had been performed in 123 (98\%) of participants' hospitals, with a median (IQR [range]) number of operations of 6 (1-25 [0-340]) children < 1 year old, 17 (7.546 [0-240]) children aged 1 to $<5$ years and $28(8-73.5$ [0-600]) children aged 5 to $<16$ years in each centre.

Level 1 Reaction data were collected from 252 (66\%) participants, with a feedback score of 10 (9-10 [5-10]) across all sessions. Level 2 Learning evaluation included MCQ and OSCE skills testing. After exclusion of the physician participants from the inaugural course, data from 357 participants were eligible for analysis. Complete pre- and post-course MCQ datasets were recorded for 333 (93\%) of participants (Table 1). Missing data were mainly due to the late arrival of course delegates. Overall, mean (SD) scores increased from 37.5 (4.7) pre-course to 43.2 (3.5) post-course, a mean score change of $5.7(95 \% \mathrm{Cl} 5.3-6.1 ; p<0.0001)$. For participants visited at follow-up, complete MCQ data were recorded for 121 (96\%) of participants. The MCQ score at follow-up was $41.5(5.0)$, a mean score increase of $4.0(95 \% \mathrm{Cl} 4.3-5.8 ; \mathrm{p}<0.0001)$ when compared with pre-course scores. Pre- and post-course OSCE skills tests were complete for 311 (87\%) of eligible candidates. Missing data were mainly due to late arrival of course delegates and lost data sheets. Overall, scores increased from 5.7 (2.0) pre-course to 8.0 (1.5) post-course, a mean score change of $2.3(95 \% \mathrm{Cl} 2.1$ $2.5 ; p<0.0001)$. For participants visited at follow-up, complete OSCE skills data were recorded for $119(94 \%)$ participants. OSCE scores at follow-up were $8.3(1.4)$, showing a mean score increase of $2.7(95 \% \mathrm{Cl} 2.4-3.0$; $p<0.0001)$ compared with pre-course scores.

Level 3 Behaviour was evaluated from follow-up interviews, including a review of the participant's SAFE logbook. One hundred and twenty-six (99\%) participants visited at follow-up completed a structured qualitative interview with the SAFE fellow. Content analysis of interview data identified six broad domains of behaviour change: preparation; peri-operative care; resuscitation; management of the sick child; communication; and teaching (Table 3). Regarding preparation, participants highlighted changes to their preassessment of children $(n=16)$, fasting before surgery $(n=16)$ and changes to anaesthetic equipment $(n=32)$, such as ensuring there is 'always an Ambu ${ }^{\circledR}$ bag and correctly sized endotracheal tubes before starting' (anaesthetist, Malawi). Within the domain of peri-operative care, participants discussed making improvements to warming during surgery $(n=10)$, improved fluid management $(n=13)$, improved analgesia management $(n=21)$ and changes to their drug dosing $(n=27)$. Examples included 'giving drugs according to the weight of the child' (anaesthetist, Malawi) and 'using multimodal analgesia' (anaesthetist, Uganda). Within the domain of resuscitation, 12 participants discussed improved basic life support in children, and 35 highlighted improvements in neonatal resuscitation. On management of the sick child, participants discussed reducing drug doses for these patients $(n=9)$, and using a structured approach to assess these children 
$(n=31)$. Improved communication was a common theme, highlighted by 34 participants at follow-up, such as making sure that 'people can speak up if they have a problem' (anaesthetist, Malawi).

\section{Discussion}

The SAFE paediatric anaesthesia course is the first anaesthesia short course that addresses the training needs of non-physician anaesthetists caring for children in LMICs. This paper describes the educational impact following delivery and expansion of the course in five East African countries. Three hundred and eighty-one anaesthesia providers were trained over a 15-month period, with the majority of the 59 new faculty members going on to deliver a SAFE course, mentored by international trainers. Course evaluation data showed that this three day course was relevant to participants, and led to improvements in knowledge and skills. Encouragingly, we have shown that both knowledge and skills improvements were maintained at follow-up months later, as well as finding evidence of a number of positive changes in workplace behaviour.

Children have a significantly higher peri-operative risk in LMICs than in high resource settings [13-17]. The reasons for this are multifactorial, but include increased severity of illness because of poor access to surgery, low numbers of physician anaesthetists, limited training for non-physician providers, limited continuing professional development opportunities, and poor equipment and drug supplies [10, 15, 18-21]. The SAFE paediatric anaesthesia course was developed in response to the need for training and continuing professional development opportunities. Qualitative interviews conducted three to six months following training showed changes in behaviour relating to pre-operative preparation, peri-operative care, resuscitation, management of the sick child, communication and teaching, all factors associated with improved outcomes after surgery. Participants described changes in practice that reflect the specific needs of children, such as adoption of appropriate fasting times, weight-based administration of drugs, recognition of the need to procure appropriate equipment, and improved knowledge and resuscitation skills, which are all factors known to be associated with improved outcomes.

Short courses are one method to address training gaps, and have encouraging results [7, 22-24]. Systematic review and meta-analysis of attendance at adult advanced cardiac life support courses have been shown to have a positive effect on patient outcomes [22]. Maternal outcomes were improved following delivery of the Advanced Life Support in Obstetrics course in four low-income countries [23]. Additionally, evaluation of the Primary Trauma Course showed evidence of improved individual management of cases, and also resulted in beneficial effects at the participants' host institutions in terms of staffing, equipment and training [7]. The SAFE paediatric anaesthesia course was developed along the same lines as the SAFE obstetric anaesthesia course (9), with care taken to ensure the materials were tailored to the needs of participants. This project used a scaling-up method to implement training in five countries, using coaching and mentorship by experienced trainers to maintain the quality of the training delivered and strengthen existing international and regional partnerships. 
There may be a number of limitations to our approach. The course was developed by physician anaesthetists, and the content may not be optimal for non-physician course participants. Feedback was obtained at all stages of course development to check relevance to the participants, and modified accordingly. Knowledge assessment using MCQ testing is only one measure of learning and, although piloted during course development, there may still have been limitations in both understanding of questions and MCQ technique. A possible factor for an improvement in the OSCE testing may be increased familiarity with the manikins during the course teaching, or unconscious bias by the assessors. We aimed to minimise this by ensuring that stations were standardised, and using a structured scoring system. Not all participants were visited in their workplace, and this may have introduced bias into follow-up data. However, significant effort was made to visit participants in a range of health facilities and grades. Finally, changes in behaviour described at followup were self-reported, and may be vulnerable to reporting bias. Course participants were not observed in the workplace before training, and no attempt was made to collect patient outcomes before and after training. However, wherever possible, information that was reported was triangulated during the visit to the work environment. Translating knowledge into practice is an important outcome of training, and course participants provided specific examples of change in practice, with adoption of new procedures and protocols. Further research, therefore, should focus on collecting more evidence of behaviour change and influences on change, as well as linking behaviour change with impact on patient outcome.

In summary, the SAFE paediatric anaesthesia course is the first short course focussing on paediatric anaesthesia that is specifically designed for anaesthesia providers in LMICs. We describe successful implementation to providers from a range of hospital settings, resulting in improvements in knowledge and skills that were retained over time, as well as positive changes in behaviour at institutional level. The SAFE paediatric anaesthesia course is an effective way to deliver training in paediatric anaesthesia, and could be adopted more widely to help strengthen emergency and essential surgical care for children as a component of universal health coverage in LMICs.

\section{Acknowledgements}

We would like to acknowledge the following for their significant contributions to this project: J. Kiwanuka, S. Mndolo, Z. Burton, G. Rodney, F. Evans, D. Bould, A. Ahmed and M. White. Funding for this project was obtained from UK Aid administered by the Tropical Health Education Trust (THET), with additional contributions from Smile Train and the Association of Anaesthetists. No competing interests declared. 


\section{References}

1. Meara JG, Leather AJM, Hagander L, et al. Global Surgery 2030: evidence and solutions for achieving health, welfare, and economic development. The Lancet 2015; 386: 569-624.

2. Debas HT, Donkor P, Gawande A, Jamison DT, Kruk ME, Mock CN. Essential Surgery. Disease Control Priorities. Third edition. Volume 1. Washington DC: World Bank Group; 2015. Available at: http://dcp3.org/surgery. Accessed 9th April 2019.

3. World Health Assembly Resolution 68.15. Strengthening emergency and essential surgical care and anaesthesia as a component of universal health coverage. Sixty-Eighth World Health Assembly. Available at: http://apps.who.int/gb/ebwha/pdf files/WHA68/A68 R15-en.pdf. Accessed 9th April 2019.

4. Bickler SW, Telfer ML, Sanno-Duanda B. Need for paediatric surgery care in an urban area of The Gambia. Tropical Doctor 2003; 33: 91-4.

5. Kempthorne P, Morriss WW, Mellin-Olsen J, Gore-Booth J. The WFSA Global Anesthesia Workforce Survey. Anesthesia Analgesia 2017; 125: 981-90.

6. Bosenberg AT. Pediatric anesthesia in developing countries. Current Opinion in Anesthesiology 2007; 20: 204-10.

7. Ologunde R, Le G, Turner J, et al. Do trauma courses change practice? A qualitative review of 20 courses in East, Central and Southern Africa. Injury 2017; 48: 2010-6.

8. Goucke CR, Jackson T, Morriss W, Royle J. Essential Pain Management: An Educational Program for Health Care Workers. World Journal of Surgery 2014; 39: 865-70.

9. Livingston PE, F.; Nsereko, E.; Nyirigira, G.; Ruhato, P.; Sargeant, J. Safer obstetric anesthesia through education and mentorship:a model for knowledge translation in Rwanda. Canadian Journal of Anesthesia 2014; 61: 1028-39.

10. Walker IA, Obua AD, Mouton F, Ttendo S, Wilson IH. Paediatric surgery and anaesthesia in southwestern Uganda: a cross-sectional survey. Bulletin of the World Health Organization 2010; 88: 897-906.

11. Kirkpatrick D, Kirkpatrick J. Evaluating Training Programs: The Four Levels. Third Edition. California: Berrett-Koehler Publishers; 2006.

12. Hsieh HF, Shannon SE. Three approaches to qualitative content analysis. Qualitative Health Research 2005; 15: 1277-88.

13. Murat I, Constant I, Maud'huy H. Perioperative anaesthetic morbidity in children: a database of 24,165 anaesthetics over a 30-month period. Pediatric Anesthesia 2004; 14: 158-66.

14. GlobalSurg Collaborative. Determinants of morbidity and mortality following emergency abdominal surgery in children in low-income and middle-income countries. BMJ Global Health 2016; 1: e000091.

15. Ouro-Bang'na Maman AF, Kabore RA, Zoumenou E, Gnassingbe K, Chobli M. Anesthesia for children in Sub-Saharan Africa--a description of settings, common presenting conditions, techniques and outcomes. Pediatric Anesthesia 2009; 19: 5-11.

16. Zoumenou E, Gbenou $S$, Assouto $P$, et al. Pediatric anesthesia in developing countries: experience in the two main university hospitals of Benin in West Africa. Pediatric Anesthesia 2010; 20: 741-7. 
17. Ahmed A, Ali M, Khan M, Khan F. Perioperative cardiac arrests in children at a university teaching hospital of a developing country over 15 years. Pediatric Anesthesia 2009; 19: 581-6.

18. Ameh EA, Dogo PM, Nmadu PT. Emergency neonatal surgery in a developing country. Pediatric Surgery International 2001; 17: 448-51.

19. Uba AF, Chirdan LB, Ituen AM, Mohammed AM. Typhoid intestinal perforation in children: a continuing scourge in a developing country. Pediatric Surgery International 2007; 23: 33-9.

20. Walker IA, Bashford T, Fitzgerald JE, Wilson IH. Improving Anesthesia Safety in Low-Income Regions of the World. Current Anesthesiology Reports 2014; 4: 90-9.

21. Hodges SC, Mijumbi C, Okello M, McCormick BA, Walker IA, Wilson IH. Anaesthesia services in developing countries: defining the problems. Anaesthesia 2007; 62: 4-11.

22. Lockey A, Lin Y, Cheng A. Impact of adult advanced cardiac life support course participation on patient outcomes-A systematic review and meta-analysis. Resuscitation 2018; 129: 48-54.

23. Dresang LT, Gonzalez MM, Beasley J, et al. The impact of Advanced Life Support in Obstetrics (ALSO) training in low-resource countries. International Journal of Gynecology and Obstetrics 2015; 131: 209-15.

24. Benito J, Luaces-Cubells C, Mintegi S, et al. Evaluation and Impact of the "Advanced Pediatric Life Support" Course in the Care of Pediatric Emergencies in Spain. Pediatric Emergency Care 2018; 34: 628-32. 


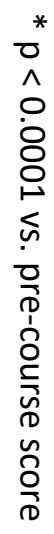




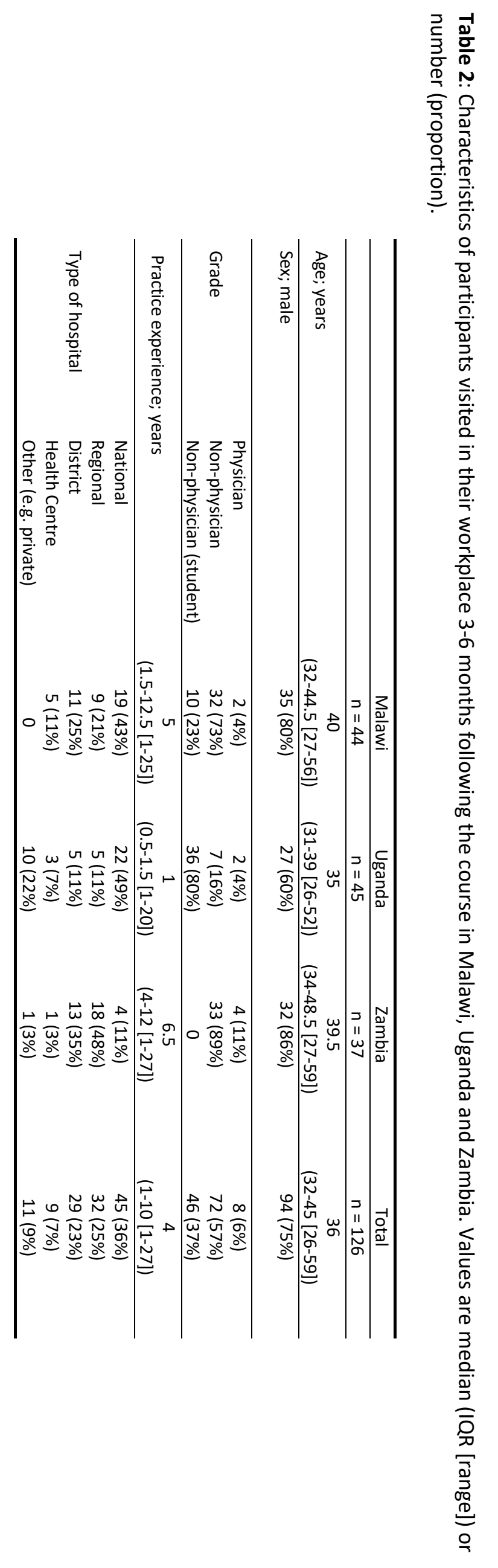




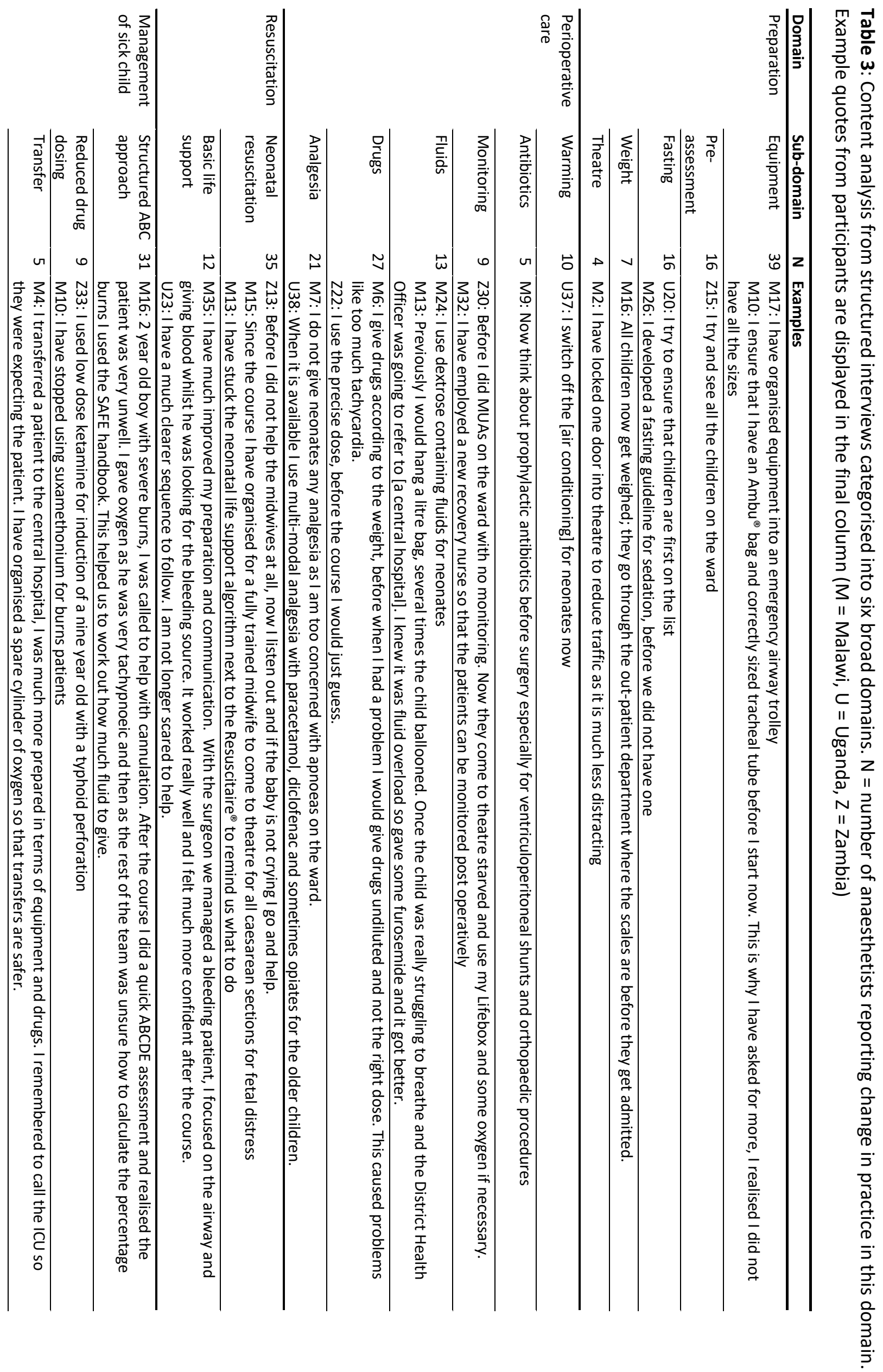


Caption for figure:

Figure 1: Flowchart showing sequence of courses delivered.

SAFE, Safer Anaesthesia From Education; TTT, Train-the-Trainer 